\title{
Immediate Effect of Neurodynamic Tensioner Versus Proprioceptive Neuromuscular Facilitation Stretch on Subjects with Short Hamstring Syndrome
}

\author{
SAFAA M. SADEK, M.Sc.; RAGIA M. KAMEL, Ph.D. and MARWA Sh. SALEH, Ph.D.
}

The Department of Basic Sciences, Faculty of Physical Therapy, Cairo University

\begin{abstract}
Background: Decreased flexibility of Hamstrings has a negative impact on the posture of lumbo-pelvic region and may serve as a cause of low back pain. It is also a major contributing factor for lumbar spine disorders, hamstring strains and other sports related injuries.

Aim of Study: Tocompare the effects of (NT) Neurodynamic Tensioner and (PNF) hold-relax stretching on hamstring flexibility in order toidentify the most effective intervention for short hamstring syndrome.
\end{abstract}

Material and Methods: Present study conducted as Pretest - Post-test Experimental study.

Participants:Forty subjects with short hamstring syndrome participated in this study. Subjects were subdivided into two matched groups; each group consisted of twenty subjects, group A who received neural tensioner in slump position; and group B who received the PNF (hold-relax) stretching.

Outcome Measure: Knee extension angle (KEA) in degrees was measured using the Active Knee Extension (AKE) test with using a digital goniometer.

Results: There was no significant difference in the KEA between group $\mathrm{A}$ and $\mathrm{B}$ pretreatment $(p=0.75)$. There was no significant difference in the KEA between group A and B post treatment $(p=0.38)$.

Conclusions: Neurodynamic tensioner and PNF (holdrelax) stretching are equally effective in increasing hamstring flexibility immediately in subjects with short hamstring syndrome.

Key Words: Hamstring flexibility - Neurodynamic tensioner - PNF-Active knee extension test.

\section{Introduction}

FLEXIBILITY is an important factor in physical fitness that enables smoothly and safety movement [1]. Hamstring muscles have an important role in the performance of daily activities such as control-

Correspondence to: Dr. Safaa M. Sadek, The Department of Basic Sciences, Faculty of Physical Therapy, Cairo University led trunk movement, walking, and jumping [2]. So, hamstrings flexibility have been successfully prescribed for relief of low back pain which was found to be increased in subjects' with hamstring tightness.

Any alterations in muscular flexibility could directly influence the function of other joints in the kinetic chain. So, optimal muscular flexibility and joint range of motion (ROM) are necessary for optimal physical (strength, endurance and fitness) and psychosocial wellbeing [3]

The hamstrings act as a mechanical interface surrounding the sciatic nerve. Nerve adhesions in the hamstring may alter neurodynamics and cause abnormal mechanosensitivity of the sciatic nerve; which could influence hamstring flexibility. Neural tissues involvement to hamstring flexibility has been studied in the literature [4,5]. Neural Mobilization (NM) or Nerve Glide Stretches are active stretches in which the nervous system is made taut and then slack which explain the observed increase in flexibility [5], through decreasing neural mechanosensitivity by providing movement that lead to changes in the neurodynamics and modification of sensation.

The primary effect of neural mobilisation is to restore the dynamic balance between movement of neural tissues and surrounding mechanical interfaces, which allow reducing the intrinsic pressures on the neural tissues and promoting optimal physiological function [6].

As reported in the study conducted by Sharma et al. [14], neural tensioner is effective as an adjunct to static stretching on improving hamstring flexibility as compared to static stretching alone. So,the results of this study reinforce previous studies that showed improvement in lower quarter flexibility 
following different neural mobilization techniques such as active slump tensioners [8].

Proprioceptive Neuromuscular Facilitation (PNF) is a more advanced form of flexibility training that involves both the stretching and contraction of the target muscle group, While there are several variations of PNF stretching, they all have one thing in common; they facilitate muscular inhibition [9].

Proprioceptive Neuromuscular Facilitation (hold-relax) stretching, provides the greatest potential for muscle lengthening, under the assumption that greater motor pool inhibition reduces muscle contractibility and therefore allows more muscle compliance [10]. Numerous investigations established PNF techniques are more effective than traditional stretching exercises for range of motion or flexibility enhancement [9].

O'tlora et al. [11] conducted a study on efficacy of static stretching and PNF stretch on hamstrings length after a single session and concluded that PNF results into increase in hamstring flexibility. these positive effects of neurodynamic tensioner and PNF in improving the hamstring flexibility, up till now no studies have been conducted to determine which one of them is the most effective so, thisstudy was conducted to compare between neurodynamic tensioner in slump position and PNF (hold-relax) stretching in improving hamstring flexibility on subjects with short hamstring syndrome.

Considering the importance of hamstring flexibility in general and athletic population, maintaining the flexibility of hamstring muscle is of utmost importance for health care professionals and to achieve this goal one needs to know the most effective and efficient technique to gain hamstring flexibility. Numerous studies have shown the individual effectiveness of Neurodynamic tensioner in slump position and PNF (hold-relax) in improving the flexibility of hamstring muscle but there are no studies which shows the superiority of one technique with respect to the other, hence the purpose of the study is to compare the effectiveness of Neurodynamic tensioner in slump position versus PNF (Hold-Relax) technique in improving the hamstring flexibility in subjects with short hamstring syndrome.

\section{Material and Methods}

This study was a comparative experimental trial. Approval to conduct the study was obtained from the ethics committee of the Faculty of Physical
Therapy, Cairo University with approval number (18-7-2019). Informed consent was received prior to the intervention from each subject. Forty subjects, of both sexes with short hamstring syndrome were recruited from students of Faculty of Physical Therapy, Cairo University and colleagues of physiotherapists at Physical Therapy Department in Menya-El Qamh Hospital.

Forty subjects with short hamstring syndrome participated in this study. Subjects were subdivided into two matched groups, each group consisted of twenty subjects. The first group was the group A who received neural tensioner in slump position; the second group was the group B who received the hold-relax for hamstring muscle.

Inclusion criteria: Subjects were included in the study if they had Aged from 18-30 years [12]. with hamstring tightness of 20 . (inability to achieve greater than 160 . of knee extension with hip at 90. of flexion) [13]. Also, subjects were selected with right lower limb dominance [14]. With normal body mass index (BMI).

Exclusion criteria: Subjects were excluded if they had any neurological or orthopedic diseases affecting their lower extremity, Traumatic hamstring injury, Acute or chronic low back pain or Who already involved in any exercise programs for lower extremity in the last three months. All subjects were screened according to the inclusion and exclusion criteria, and randomly assigned into two equalgroups (20 each); the neurodynamic group and PNF (hold relax) group.

Measurements for both groups were taken as a baseline pre intervention. Assessment was done immediately at the same sessionpost intervention.

\section{Outcome measurement:}

Measurements of hamstring flexibility were obtained using the Active Knee Extension (AKE) test. The active knee extension Fig. (1) is a measure of hamstring flexibility; it had been performed while the participant lies supine on the examination table wearing shorts [15]. With the dominant (tested) hip and knee flexed to 90. degrees, held in position by a wooden box, measuring $44.5 \mathrm{~cm}$ wide, $42 \mathrm{~cm}$ high and $20 \mathrm{~cm}$ deep was secured to the table with two Velcro straps; a third strap was used to secure the participant's thigh and box, to maintain dominant limb in 90 degree flexion and the non-tested lower extremity secured to the table by Velcro strap across the middle of the thigh to minimize hip flexion during the procedure. While the participant maintaining a relaxed foot position, he was 
asked to extend his knee as far as he's comfortably able, keeping the posterior aspect of the thigh in contact with box and stop at the point where he first felt the stretch sensation within the posterior thigh areaand hold the position for about 5 seconds. [16]. The angle of the knee extension was measured using a digital goniometer by measuring the angle between a line drawn from the mark just distal to
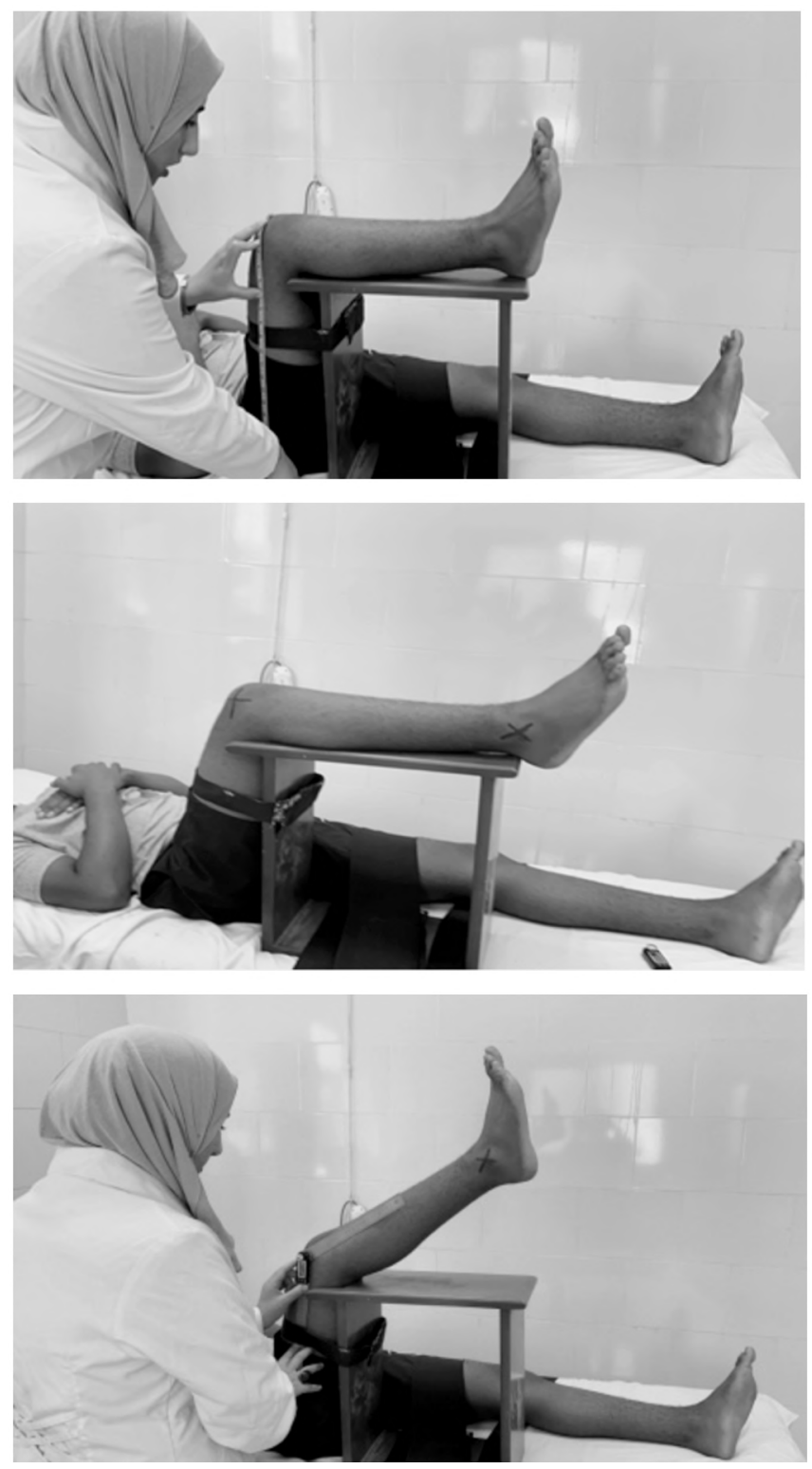

the greater trochanter and the mark on the femoral condyle, with other line drawn from the mark on the fibular head to a mark just proximal to the lateral malleolus by using tape measurement. A total of 3 measurements were recorded and a mean angle of the extension will be recorded for analysis. AKE was found to be valid and reliable for measuring of hamstring muscle length [17].
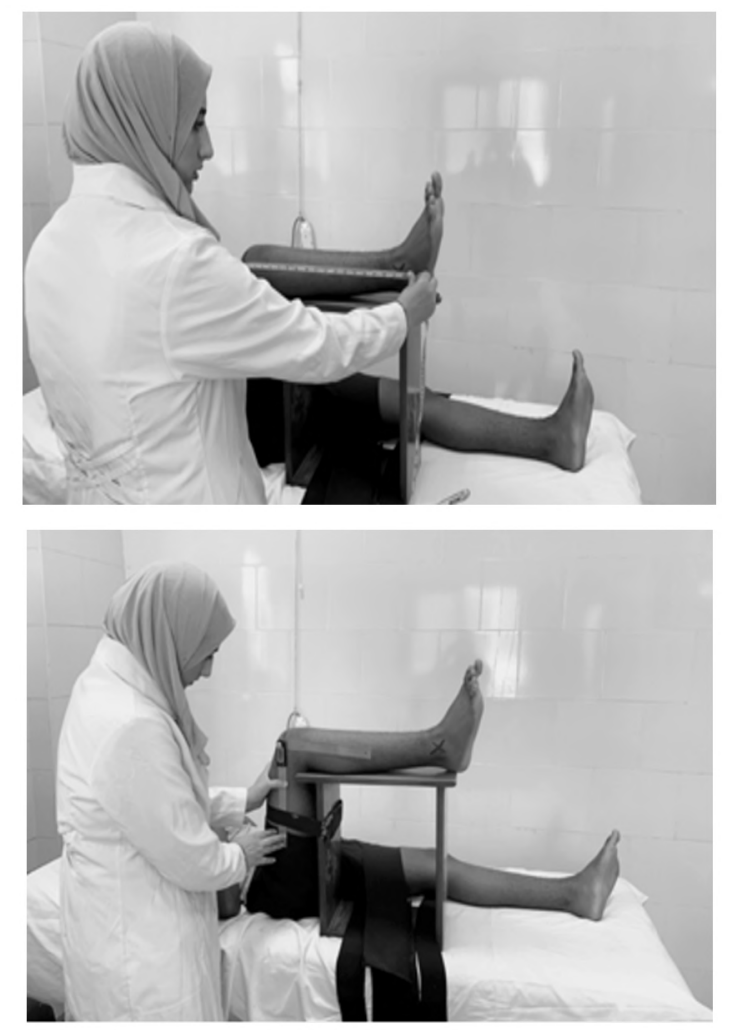

Fig. (1): Active knee extension test.

\section{Intervention:}

The neurodynamic tensioner:

The participants received NT technique on the sciatic nerve of the dominant leg as shown in Fig. $(2 \mathrm{~A}, \mathrm{~B})$ (a. starting position) started with the subject in high sitting, cervical spine extended, both hands relaxed anteriorly with flexion of both knees then the subject is asked to maintain a thoracic slump, and clasped both hands posteriorly at lumbosacral level; the investigator passively flexed the cervical spine with simultaneous extension of the knee with foot maintained in neutral position to dorsiflexion 
(b. end position). The end position of neural tensioner was maintained for 60 seconds followed by 10 seconds rest. The cervical spine then was extended with flexion of the knee, and the spine was straightened in the rest period to avoid any back pain. Total 5 sets were done, each set consist of one repetion [18]

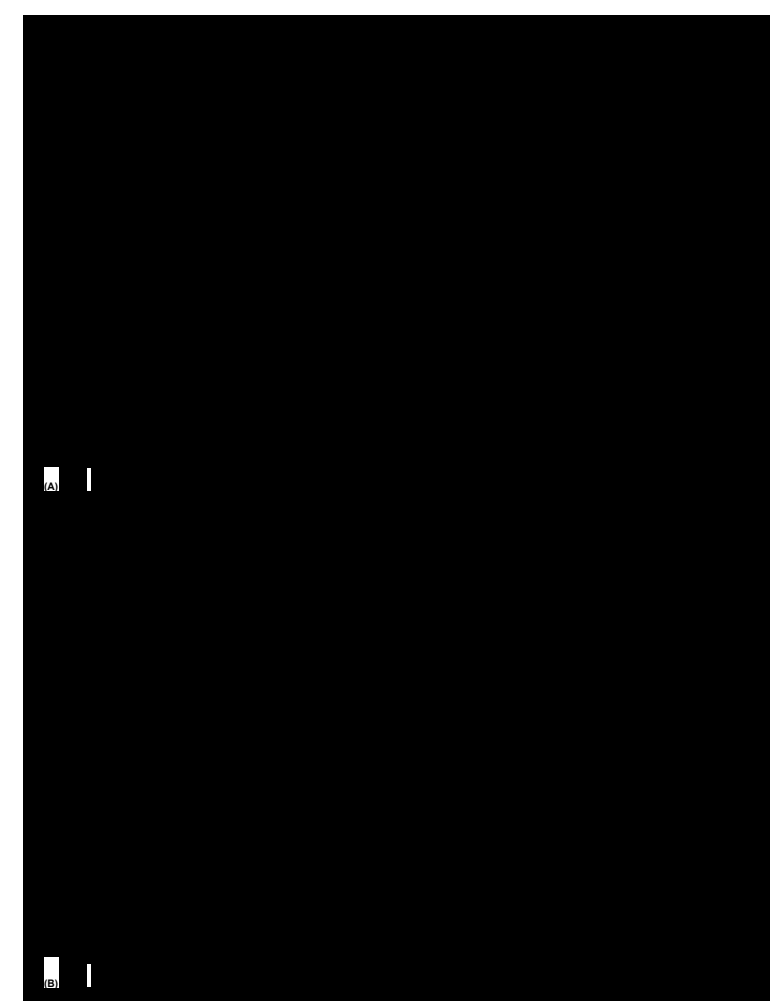

Fig. (2): Tensioner technique: (A) Starting position; (B) End position.

\section{PNF (Hold-relax) stretch:}

The participants received hold-relax, as shown in (Fig. 3). Subjects were in supine position with their non-dominant lower extremity was strapped down the table. Predetermined time intervals for stretching, contracting and relaxing will be used to standardize the method utilizing a stop watch. For each stretch, the therapist stretched the hamstring muscle by passively flexing the hip with knee fully extended, allowing no hip rotation. The hamstring muscle was stretched until the subject reported the first mild stretch sensation; this position was held for $7 \mathrm{sec}$. Next, the subject then isometrically contracted the hamstring muscle for $3 \mathrm{sec}$ by attempting to push his leg down towards the table against the resistance of the therapist. Following this, the subject asked to relax for $5 \mathrm{sec}$. The therapist then passively stretched the muscle until a mild stretch sensation was reported. This stretch was hold for $7 \mathrm{sec}$. This sequence repeated 5 times with each sequence separated from each by a 20 second interval [9].

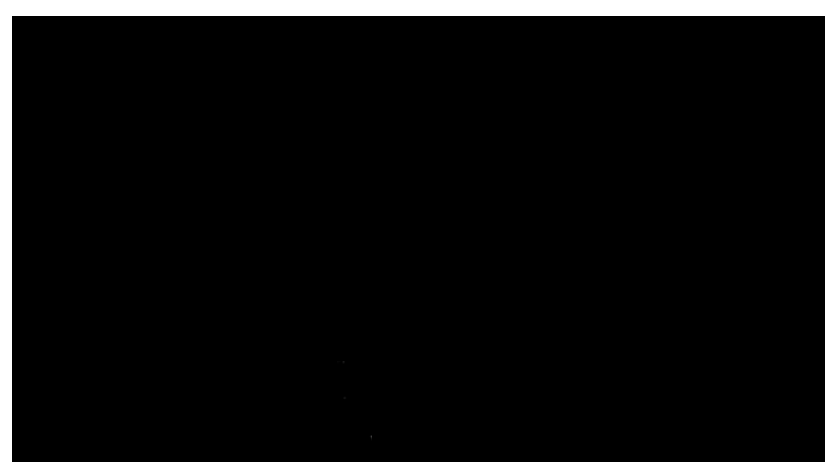

Fig. (3): PNF (hold-relax) technique.

\section{Sample size:}

Sample size calculation was performed prior to the study using $\mathrm{G}^{*}$ POWER statistical software (version 3.1.9.2; Franz Faul, Universitat Kiel, Germany) and revealed that the appropriate sample size for this study was $n=40$. Calculations were made using $a=0.05,0=0.2$ and large effect size $=0.91$ and alloctation ratio $\mathrm{N} 2 / \mathrm{N} 1=1$.

\section{Statistical analysis:}

Descriptive statistics and Unpaired $t$-test were conducted for comparison of subjects characteristics between both groups. Chi-squared test was used for comparison of sex distribution between groups. Normal distribution of data was checked using the Shapiro-Wilk test. Levene's test for homogeneity of variances was conducted to ensure the homogeneity between groups. Unpaired $t$-test was conducted to compare the mean values of KEA between group A and B. Paired $t$-test was conducted for comparison between pre and post treatment in each group. The level of significance for all statistical tests was set at $p<0.05$. All statistical analysis was conducted through the statistical package for social studies (SPSS) version 22 for windows (IBM SPSS, Chicago, IL, USA).

\section{Results}

\section{Subject characteristics:}

Table (1) showed the subject characteristics of both groups. There was no significant difference between both groups in the mean age, weight, height and BMI $(p>0.05)$. Also, there was no significant difference in sex distribution between groups $(p=0.7)$. 
Table (1): Comparison of subject characteristics between group A and B.

\begin{tabular}{|c|c|c|c|c|c|}
\hline & \multicolumn{2}{|c|}{$\mathrm{X} \pm \mathrm{SD}$} & \multirow{2}{*}{ MD } & \multirow{2}{*}{$\begin{array}{c}t- \\
\text { value }\end{array}$} & \multirow{2}{*}{$\begin{array}{c}p- \\
\text { value }\end{array}$} \\
\hline & Group A & Group B & & & \\
\hline Age (years) & $23.6 \pm 3.85$ & $24.8 \pm 3.31$ & -1.13 & -0.77 & 0.44 \\
\hline Weight $(\mathrm{kg})$ & $63.95 \pm 9.52$ & $61.85 \pm 12.04$ & 0.67 & 0.39 & 0.69 \\
\hline Height $(\mathrm{cm})$ & $168.6 \pm 7.91$ & $166 \pm 10.86$ & 1.07 & 0.95 & 0.34 \\
\hline BMI $\left(\mathrm{kg} / \mathrm{m}^{2}\right)$ & $22.37 \pm 1.8$ & $22.21 \pm 1.81$ & -0.11 & -0.15 & 0.88 \\
\hline Males/females & $9 / 11$ & $8 / 12$ & & $\left(\chi^{2}=0.1\right)$ & 0.74 \\
\hline $\begin{array}{l}\mathrm{X}: \text { Mean. } \\
\text { SD : Standard } \\
\text { MD : Mean diff }\end{array}$ & $\begin{array}{l}\text { deviation. } \\
\text { erence. }\end{array}$ & $\begin{array}{l}\chi^{2} \\
p \text {-value } \\
\text { BMI }\end{array}$ & $\begin{array}{l}\text { Chi sq } \\
\text { Probal } \\
\text { Body }\end{array}$ & $\begin{array}{l}\text { lared value. } \\
\text { ility value. } \\
\text { lass index. }\end{array}$ & \\
\hline
\end{tabular}

Effect of treatment on Knee extension angle:

- Within group comparison:

There was a significant increase in KEA post treatment in both groups compared with that of pretreatment $(p>0.001)$. The percent of increase in KEA in the group A and B groups were 8.72 and $7.6 \%$ respectively.

\section{- Between groups comparison:}

There was no significant difference in KEA between both groups pre-treatment $(p>0.05)$. Also, Comparison between groups post treatment revealed non-significant difference in KEA $(p>0.05)$.

Table (2): Mean of Knee extension angle pre and post treatment of both groups.

\begin{tabular}{llllll}
\hline KEA (degrees) & $\begin{array}{l}\text { Group A } \\
\mathrm{X} \pm \mathrm{SD}\end{array}$ & $\begin{array}{c}\text { Group B } \\
\mathrm{X} \pm \mathrm{SD}\end{array}$ & MD $(95 \% \mathrm{CI})$ & $\begin{array}{c}t- \\
\text { value }\end{array}$ & $\begin{array}{c}p \text { - } \\
\text { value }\end{array}$ \\
\hline Pre treatment & $137.72 \pm 7.4$ & $136.9 \pm 8.86$ & $0.82(-4.39: 6.05)$ & 0.32 & 0.75 \\
Post treatment & $149.74 \pm 8.05$ & $147.3 \pm 9.41$ & $2.44(-3.17: 8.04)$ & 0.87 & 0.38 \\
MD (95\% CI) & $-12.02(-13.92:-10.11)$ & $-10.4(-11.6:-9.22)$ & & & \\
$\%$ of change & $8.72 \%$ & $7.6 \%$ & & \\
$t$-value & -13.21 & -18.26 & & \\
& $p=0.001$ & $p=0.001$ & & \\
\hline
\end{tabular}

\begin{tabular}{lll}
\hline $\mathrm{X}:$ Mean. & $\mathrm{CI}$ & : Confidence interval. \\
SD : Standard deviation. & $p$-value & Level of significance. \\
MD : Mean difference. & KEA & $:$ Knee extension angle
\end{tabular}

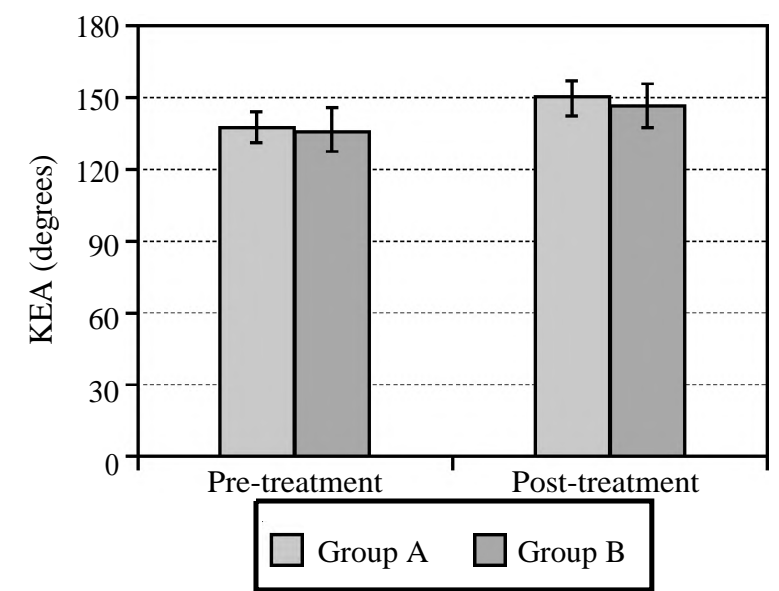

Fig. (4): Mean KEA pre and post-treatment of the group $\mathrm{A}$ and $\mathrm{B}$.

\section{Discussion}

Muscular flexibility is an important aspect of normal human function. Limited flexibility has been shown to predispose a person to several musculoskeletal overuse injuries and significantly affect a person's level of function. To prevent muscle injuries, stretching exercises are usually recommended [19]. Reasons for stretching relate to beliefs that stretching exercises will increase flexibility and decrease muscle stiffness [20].
The purpose of this study was to investigate the immediate effect of neurodynamic tensioner versus PNF (hold-relax) stretch on subjects with short hamstring syndrome.

Results of the current study showed that: Neurodynamic tensioner and hold-relax were individually very effective, There was significant immediate improvement in hamstring flexibility which was depicted by increase range of motionmeasured by active knee extension test using a digital goniometer a significant increase in KEA post treatment in the group A and B compared with that pretreatment $(p>0.001)$. While there was no significant difference between both groups post treatment in KEA $(p>0.05)$.

In group $\mathrm{A}$, which received neurodynamic tensioner the mean AKE was improved significantly, this result of the current study is supported by the study done by Herrington et al. [21], who states that knee extension range of motion can be improved by adding tensioner technique in slump position.

As reported in a study conducted by Sharma et al. [7], neural tensioner is effective as an adjunct to static stretching on improving hamstring flexibility as compared to static stretching alone. The 
results support our hypothesis that addressing neural structures along with muscle tissue (hamstring) can improve KEA, an indicator of posterior thigh flexibility. Lastly, the results of this study reinforce previous studies that showed improvement in lower quarter flexibility following different neural mobilization techniques such as active slump tensioners [8].

The probable reason of improved KEA post neural stretch can be attributed to the improved physiological functions of nervous system, including improved axoplasmic flow and reduced neural mechano sensitivity [5]. This explanation can be supported by previous studyconducted by Ellis et al. [22] using high resolution ultrasound which concluded that the neural mobilization exercises (sliders and tensioners) produce significant excursion of the sciatic nerve at the posterior mid-thigh.

McHugh et al. [23] established that when neural tension (thoracic and cervical flexion) is added to a hamstring stretch, the increased stretch sensation is not caused by contractile tissue response or increased EMG activity. The main changes in contractile response occur during the last 10 degrees of movement. Therefore neural tension is responsible for the increased stretch sensation during range.

In group B, which received PNF (hold-relax) the mean AKE was improved significantly. Possible explanation for the improved hamstring flexibility for the subject in group B could be caused by the effect of PNF which has been attributed to neurophysiological and mechanical factors [24]. The neurophysiological foundation of stretching is based on the neural inhibition of the muscle undergoing stretching. The Golgi tendon organ (GTO) is a nerve receptor that fires when tension increases in the tendon. This tension can be due to stretch or muscle contraction when the GTO fires a signal that is sent to the spinal cord, causing the agonist muscle to relax. This can increase the ROM by autogenic inhibition of the target muscle [9]. As a mechanical factor, the muscle-tendon unit (MTU) is believed to respond viscoelastically during the stretching maneuver [24]. Viscous and elastic mechanical properties refer to the response of the tissue load, which is a property of the viscous and elastic components. The elastic component is the ability of the tissue to return to the previous form after deformation. The viscous component is related to the fluid part of the muscle, which deviates in response to mechanical force [25]. The viscous property within an MTU elongates in response to a slow sustained force and will resist rapid changes in length. While the MTU is under stretch, the amount of force generated by the viscous component to resist the elongation decreases over time (stress relaxation) [7,14]. When the force attempting to lengthen the MTU is sustained, the MTU gradually elongates (creep) [7]

During PNF stretching (hold-relax) autogenic inhibition of the target muscle takes place. Moore and colleagues [26] approved the theoretical basis of PNF stretching and proposed that the relax portion of hold-relax maneuver should be applied quickly after the hold position. Therefore the results of this study can be correlated with the popular belief that PNF stretching techniques lead to relaxation/inhibition of the stretched muscle via the two physiological mechanisms proposed by Sherrington namely reciprocal inhibition and autogenic inhibition.

Also, positive effects of PNF stretching techniques of the current study is supported by study conducted by Surburg and Schrader, [27], who concluded that PNF techniques are more effective than traditional stretching exercises for range of motion or flexibility enhancement.

As reported in the study Hindle et al., [28], PNF has been shown to have a positive effect on active and passive range of motions which reinforce the results of the current study.

This explanation is supported by previous study conducted by Milad, [29]. Who states thatwhen a muscle is tight, a stimulation of the GTO will send a message to the same muscle to relax for instance, if biceps brachii muscle is contracted, a stimulation of biceps brachii tendon will send a message to the biceps to relax.

This inhibitory effect is thought to diminish muscle activity and, therefore, allow for relaxation so that the muscle can be stretched. Motor pool excitability has been measured by the Hoffman reflex during soleus muscle static stretching, contract-relax stretching, and contract-relax-agonistcontract stretching techniques. Motor pool excitability significantly diminished after the contractrelax and contract-relax-antagonist-contract methods of PNF stretching over static stretching of the soleus. This inhibitory effect has been suggested to increase muscle compliance, allowing for increased length during a stretch without stimulation of the stretch reflex [14]. Hence neurodynamic tensioner and PNF have an immediate effect on hamstring flexibility Thus, both the stretching can be used in clinical practicefor improving the flexibility of hamstring muscle. 


\section{Limitations of the study:}

It appears to be difficult to generalize the results of this study due to the small number of subjects. Also, this studydetermines only the immediate effects of neurodynamic tensioner and hold-relax techniques. In the future, studies on the longtermeffects of both techniques including more subjects should be performed. Also it would be very interestingto compare the effect of the two techniques in subjects with a history of hamstring injuryand low back pain.

\section{Conclusion:}

It can be concluded that neurodynamic tensioner and PNF (hold-relax) are equally effective in immediately increasing hamstring flexibility in subjects with short hamstring syndrome.

\section{Acknowledgements:}

The authors would like to acknowledge and express their thanks to all subjects who participated in this study.

\section{References}

1- ODUNAIYA N.A., HAMZAT T.K. and AJAYI O.F.: The effects of static stretch duration on the flexibility of hamstring muscles. Journal of Biomedical Research, 8: 79-82, 2005.

2- LUMBROSO D., ZIV E., VERED E. and KALICHMAN L.: The effect of kinesio tape application on hamstring and gastrocnemius muscles in healthy young adults. J. Bodyw Mov. Ther., 18:130-8, 2014.

3- LAW R.Y., HARVEY L.A., et al.: Stretch exercises increase tolerance to stretch in patients with chronic musculoskeletal pain: A randomized controlled trial. Physical Therapy, 89 (10): 1016-1026, 2009.

4- MENDEZ-SANCHEZ R., ALBURQUERQUE-SENDIN F., FERNANDEZ-DE-LAS-PENAS C., BARBERO- IGLESIAS F.J., SANCHEZ-SANCHEZ C., CALVOARENILLAS J.I., et al.: Immediate effects of adding a sciatic nerve slider technique on lumbar and lower quadrant mobility in soccer players: A pilot study. Journal of Alternative Complementary Medicine Jun, 16 (6): 669$675,2010$.

5- CASTELLOTE-CABALLERO Y., VALENZA M.C., et al.: Immediate effects of neurodynamic versus muscle stretching on hamstring flexibility in subjects with short hamstring syndrome. A pilot study. Physical Therapy in Sport, 14 (3): 156-162, 2013.

6- ELLIS R.F. and HING W.A.: Neural mobilization: A systematic review of randomized controlled trials with an analysis of therapeutic efficacy, 16 (1): 8-22, 2008.

7- SHARMAN M., CRES SWELL A. and RIEK S.: Proprioceptive Neuromuscular Facilitation Stretching: Mechanisms and Clinical Implications. Sport Med., 36 (11): 929-939, 2006.

8- WEBRIGHT W., RANDOLPH B. and PERRIN D.: Comparison of non-ballisticactive knee extension in neural slump position and static stretch techniques on hamstring flexibility. J. Orthop. Sports Phys. Ther., 26: 7-13, 1997.

9- SINGH A.K., NAGARAJ S. and PALIKHE R.M.: Neurodynamic sliding versus PNF stretching on hamstring flexibility in collegiate students: A comparative study. International Journal of Physical Education, Sports and Health, 4 (1): 29e33, 2017.

10- ETYNRE B.R. and ABRAHAM L.D.: H-reflex changes during static stretching and two variations of proprioceptive neuromuscular facilitation techniques. Clin. Neurophysiology, 63 (2): 174- 9, 1986.

11- O'TLORA, CARTWRIGHT A., WADE C.D., HOUGH A.D. and SHUM G.L.: Static stretching and PNF stretch on hamstrings length: Journal of strength and conditioning research, 25 (6): 1586-91, 2011.

12- GADPAL P. and ASGAONKAR B.: Comparison of immediate effect on hamstring flexibility using non ballistic active knee extension in neural slump position and static stretch technique. International Journal of Physiotherapy and Research, 5 (6): 2425-31, 2017.

13- DRAPER D.O., CASTRO J.L., FELAND B., SCHULTHIES S. and EGGETT D.: Shortwave diathermy and prolonged stretching increase hamstring flexibility more than prolonged stretching alone. J. Orthop. Sports Phys. Ther., 34 (1): 13-20, 2004.

14- SPERNOGA S.G., UHL T.L., ARNOLD B.L. and GANSNEDER B.M.: Duration of Maintained Hamstring Flexibility After a One-Time, Modified Hold-Relax Stretching Protocol. Journal of Athletic Training, 36 (1): 44-48, 2001.

15- FELAND J.B., MYRER J.W., et al.: Acute changes in hamstring flexibility: PNF versus static stretch in senior athletes. Physical Therapy in Sport, 2: 186-193, 2001.

16- ADEL R.A. and AHMED F.S.: Short Term Effects of Neurodynamic Stretching and Static Stretching Techniques on Hamstring Muscle Flexibility in Healthy Male SubjectsInternational Journal of Medical Research \& Health Sciences, 36-41 ISSN No: 2319-5886, 2016.

17- NORRIS C.M. and MATHEWS M.: Inter-tester reliability of a self-monitored active knee extension test. Journal of bodywork and movement therapies, 9: 256-259, 2005.

18- SHARMA S., BALTHILLAYA G., RAO R. and MANI R.: Short term effectiveness of neural sliders and neural tensioners as an adjunct to static stretching of hamstrings on knee extension angle in healthy individuals: A randomized controlled trial. Physical Therapy in Sport, 17: pp. 30-37, 2016.

19- NAGARWAL A.K., ZUTSHI K., RAM C.S. and ZAFAR R.: Improvement of Hamstring Flexibility: A Comparison between Two PNF Stretching Techniques: International Journal of Sports Science and Engineering, 4 (1): 25-33, 2010.

20- ANAP DEEPAK and BHOIR TEJASHREE: Immediate effect of mulligan bent leg raise technique versus self myofacial release on hamstring tightness in young adults Arandomized control trial. Indian Journal of Physical Therapy, 2016.

21- HERRINGTON LEE: Effect of Different Neurodynamic Mobilization Techniques on Knee Extension Range of 
Motion in the Slump Position. Journal of Manual \& Manipulative Therapy, 14 (2): 101-107, 2006.

22- ELLIS R.F. and HING W.A.: Comparison of Longitudinal Sciatic Nerve Movement With Different Mobilization Exercises: An In Vivo Study Utilizing Ultrasound Imaging, 42 (8): 667-675, 2012.

23- McHUGH M.P., JOHNSON C.D. and MORRISON R.H.: The role of neural tension in hamstring flexibility Scand J. Med. Sci. Sports Sports, 22: 164-169, 2012.

24- Magnusson S.P., Simonsen E.B., et al.: Biomechanical responses to repeated stretches in human hamstring muscle in vivo.American Journal of Sports Medicine, 24 (5): 622e628, 1996.

25- BALLANTYNE F., FRYER G. and McLAUGHLIN P.: The effect of muscle energy techniquenon hamstring extensibility: The mechanism of altered flexibility. J. Osteopath. Med., 6: 59e63, 2003.

26- MOORE A. and CARL KUKULKA G.: Depression of Hoffmann reflexes following voluntary contraction and implications for proprioceptive neuromuscular facilitation

27- SURBURG P.R. and SCHRADER J.W.: Proprioceptive neuromuscular facili-tation techniques in sports medicine: A reassessment. J. Athl Train, 32 (1): 34-9, 1997.

28- HINDLE K.B., WHITCOMB T.J., BRIGGS W.O. and HONG J.: Proprioceptive Neuromuscular Facilitation (PNF): Its Mechanisms and Effects on Range of Motion and Muscular Function. Journal of Human Kinetics, 31: 105-113, 2012.

29- MILAD H. CHANNEL: Reciprocal and Autogenic Inhibition, Video, viewed march 2015, https://www.youtube. com/watch?v=PztKO KWvnE, 2012.

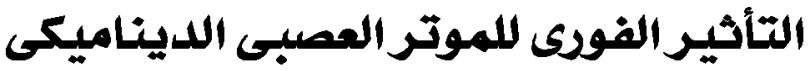

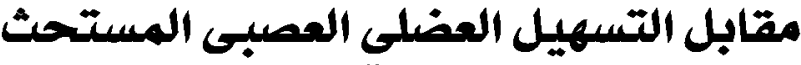

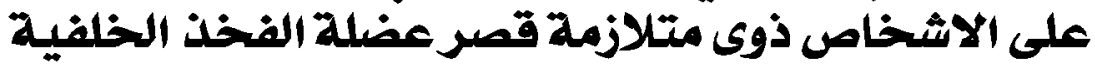

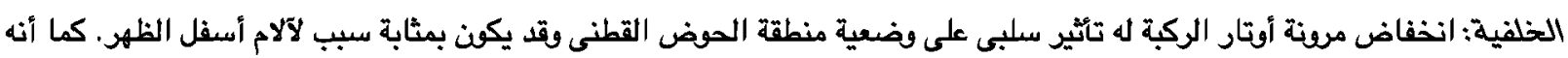
عامل رئيسى يساهم فى اضطرابات العمود الفقرى القطنى وإصابات أولى أوتار الركبة وغيرها من الإصعابات الرياضية.

الهدف: كان الهذف من هذه الدراسة هو مقارنة تأثيرات الموتر العصبى الديناميكى والتسهيل العضلى العصبى المستحث (التمدد ـ

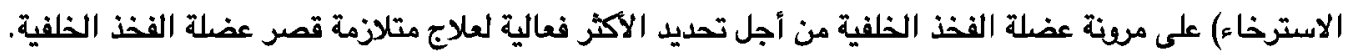

$$
\text { الأساليب: الدراسة الحالية التى أجريت كاختبار تمهيدى ـ دراسة تجريبية بعد الاختبار. }
$$

المشئاركون: شارك فى هذه الدراسة ـ ع شخصاً يعانون من متلازمة قصر عضلة الفخذ الخلفية. تم تقسيم المشاركون إلى مجموعتين

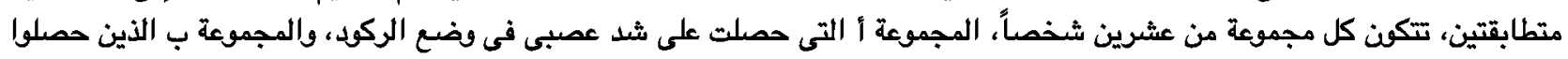
على التسهيل العضلى العصبى المستحث (التمسك ونشين والاسترخاء). فياس النتجة: تم قياس زاوية تمديد الركبة بالدرجات باستخدام اختبار تمديد الركبة النشط باستخدام مقياس الزاويا الرقمى. النتائج: لم يكن هناك فرق كبير فى زاوية تمديد الركبة بين المجموعة (أ) و (ب) قبل المعالجة (0.75= (1) لم يكن هناك فرق كبير فى زاوية

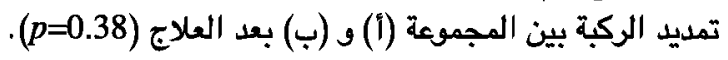

الاستتاجات: الموتر العصبى الديناميكى وإطالة التسهيل العضلى العصبى المستحث (التمسك والاسترخاء) فعالة بنفس القدر في زيادة

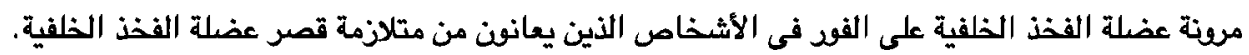

